\title{
Study of Corrosion Resistance of Laser Welded Au-Pd-Ag-In Alloy Using Electrochemical Techniques
}

\author{
Márcio L. Dos Santos ${ }^{1}$, Heloísa A. Acciari ${ }^{2}$, Carla S. Riccardi ${ }^{1}$, Antonio C. Guastaldi ${ }^{1}$ \\ ${ }^{1}$ Institute of Chemistry, Universidade Estadual Paulista, Araraquara, Brazil; \\ ${ }^{2}$ Faculdade de Engenharia de Guaratinguetá, Universidade Estadual Paulista, Guaratinguetá, Brazil. \\ Email:marcsant08@gmail.com
}

Received May 22 ${ }^{\text {nd }}, 2010$; June 26 ${ }^{\text {th }}, 2010$, accepted May 20 2011.

\begin{abstract}
The aim of this work was to evaluate the corrosion resistance of AuPdAgIn alloy, submitted to laser beam welding, in $0.9 \% \mathrm{NaCl}$ solution, using electrochemical techniques. Measures of the open circuit potential (OCP) versus time were applied to electrochemical experiments, as well as potentiodynamic direct scanning (PDS) and electrochemical impedance spectroscopy (EIS) on AuPdAgIn alloy, submitted to laser beam welding in $0.9 \% \mathrm{NaCl}$ solution. Some differences observed in the microstructure can explain the results obtained for corrosion potential, $E_{\text {corr }}$, and corrosion resistance, $R_{p}$. EIS spectra have been characterized by distorted capacitive components, presenting linear impedance at low frequencies, including a non-uniform diffusion. The area of the laser weld presented corrosion potential slightly superior when compared to the one of the base metal. The impedance results suggest the best resistant corrosion behavior for laser weld than base metal region. This welding process is a promising alternative to dental prostheses casting.
\end{abstract}

Keywords: Laser Welding, Corrosion, Au-Pd-Ag-In, Electrochemical Techniques

\section{Introduction}

The metals used in dentistry are in the form of alloys, or mixtures of one or more metal. Alloys are advantageous compared with pure metals in physical and mechanical properties because of engineering the optimum influence from each constituent [1,2]. The noble dental alloys have two or three major elemental constituents with the addition of minor elements to influence specific properties, such as the melting range, grain formation and corrosion resistance. In this context, the noble alloys may be considered in three groups: Au-Ag-Pd, low-gold alloys, including Pd-Ag and Pd-Ga, and no-gold alloys as PdCu-Ga [1]. The Au-Ag-Pd noble alloys are usually single phase, which may be hardened by solid solution strengthening. Likewise, the properties of this alloy group are generally good with acceptable strength and hardness but only moderate ductility [2]. Alloys can be joined by three similar processes: welding, brazing and soldering [3]. Welding is a joining process in which parent metals fuse and form the joint with or without a filler alloy $[4,5]$. Welds in dentistry are often accomplished with a laser. The area adjacent to the fused metal is known as the "heat affected zone," in which partial recrystallization of the alloy is probable. A decrease in hardness is noted when measured across a welded joint as a result of recrystallization. Minimizing the duration and area of heating reduces the heat affected zone [1,4].

Data on laser welding of other dental alloys are sparse and relationship between the microstructure and corrosion behavior of Au based dental casting alloys has been studied. The use of electrochemical techniques in the corrosion study is important for the understanding of its performance, biocompatibility and biofunctionality, when clinically applied, for these are constantly exposed to aggressive environments [6]. Conventional potentiodynamic direct scanning (PDS) techniques are often used. These techniques apply polarization potential on the basic corrosion potential over wide potential range. The current measurements can provide informations about the corrosion resistance and susceptibility, such as corrosion rate, passivation range and breakdown potential [7,8]. These results should be carefully considered since, with PDS, the information is not obtained in stationary conditions [8]. In rather passive systems with relatively low corro- 
sion rates (application of noble metals or systems with protective coatings), more reliable information can be usually gained from electrochemical impedance spectroscopy (EIS) measurements [7,8]. Recently, PDS technique was implemented for the characterization of corrosion systems that may exhibit strong non stationary behavior, as in pitting corrosion, flow-induced corrosion and stress-corrosion cracking [9,10]. Electrochemical impedance spectroscopy applies sinusoidal voltage signal of relatively small amplitudes (usually few tens of $\mathrm{mV}$ ), therefore the conditions of the electrodes are only slightly disturbed [11]. Besides the general corrosion properties of an investigated system, specific information about underlying electrochemical mechanisms can also be obtained from the measured impedance spectra $[8,11]$. The purpose of this work was investigate the corrosion resistance of AuPdAgIn alloy in $0.9 \% \mathrm{NaCl}$ solution, simulating the oral environment conditions, before and after submitted to the laser welding process.

\section{Experimental Part}

The AuPdAgIn alloy is a specific material applied to dental purposes, such as the production of implant prosthesis and it is classified as extra-solid [12], with chemical composition of the studied material (weight \%), by wave dispersive spectroscopy (WDS) analysis: $54.00 \pm$ $1.50 \mathrm{Au}, 2.10 \pm 0.06 \mathrm{Ag}, 36.00 \pm 1.10 \mathrm{Pd}, 8.20 \pm 0.77 \mathrm{In}$. Cylindrical test specimens, with $0.27 \mathrm{~cm}$ diameter and 1 $\mathrm{cm}$ length, were submitted to the welding process on butt joints [13]. The welding equipament, Dentaurum DL 20002S, uses a crystal Nd: YAG as source of laser, and the beam power was $5.84 \mathrm{~kW}$ in 12 milliseconds, originating a welding energy of, approximately, $70.08 \mathrm{~J}$. The test specimens were manually placed in the chamber, with shield atmosphere of argon, and spots of lap welding, in approximately $2 / 3$ of the surfaces, were applied in the whole section of the joint, with $60 \%$ of beam penetration. A precise cut disc model 15 HC DIAMOND was used to obtain the test specimens of AuPdAgIn alloy with area comprehending only the welding area, and a ISOMET 1000—BUEHLER machine was used to separate the base metal from the welding area, after the laser process. The exposed geometric areas of the welded joint and of the base metal were $0.057 \mathrm{~cm}^{2}$. The metallographic analysis of the exposed surface of the base metal and the welding area was obtained with scanning electronic microscopy (SEM), after polished with 180 to 1000 grade emery papers and alumina with granulations of $1 \mu \mathrm{m}$ and $0.3 \mu \mathrm{m}$. It was used nitromuriatic acid as chemical attack [12,13]. The working electrodes were prepared from the test specimens used on the metallographic analysis. Measures of the open circuit potential
(OCP) versus time were applied to electrochemical experiments, as well as potentiodynamic direct scanning (PDS) and electrochemical impedance spectroscopy (EIS). Electrochemical experiments were performed in a three-electrode cell containing $0.9 \% \mathrm{NaCl}$ solution at room temperature, which are appropriate to simulate corrosion under oral environment conditions. It was utilized as counter electrode Pt foil and reference electrode a saturated calomel electrode (SCE). Potentiodynamic polarization curves were recorded at $1 \mathrm{mV} \cdot \mathrm{s}^{-1}$. Impedance measurements were done at the open circuit potential, reached on the steady state, using a Solartron 1255 Frequency Response Analyser coupled to a Solartron 1287 Electrochemical Interface (Solartron Analytical Farnborough, UK), using a $10 \mathrm{mV}$ rms perturbation in the frequency range $100 \mathrm{kHz}$ to $6 \mathrm{mHz}$, five points per frequency decade and controlled by ZPlot software with analysis by ZView software (Scribner Associates, Charlottesville, USA).

\section{Results and Discussion}

Figure 1 shows micrographs obtained for Au-Pd-Ag-In alloy in the regions of the base metal (Figure 1(a)) and laser weld (Figure 1(b)). It can be observed that area of

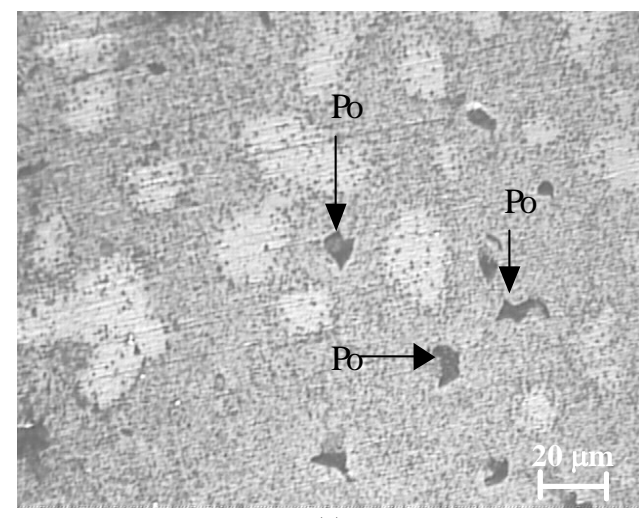

(a)

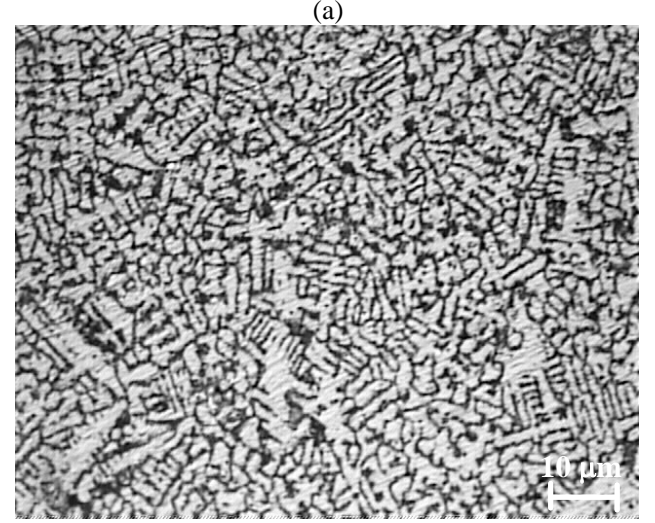

(b)

Figure 1. Light microscopy of the Au-Pd-Ag-In surfaces: (a) base metal, $P$ o = porosity; (b) laser weld. 
the base metal has a biphasic granular microstructure containing precipitates of Au. The laser weld presents a refined dendritical microstructure. The high speedy cooling imposed by the laser weld due to process of located fusion, followed by a fast cooling $\left(3.02 \times 10^{3 \circ} \mathrm{C} \cdot \mathrm{s}^{-1}\right)$ during the welding, which does not allow the microstructure to return to its initial granular structure.

Figure 2 illustrates the open circuit potential versus time curves for the base metal and laser weld areas of the Au-Pd-Ag-In. The stabilization of the potential value was observed 3 hours after immersion for both areas. The corrosion potential in the steady state does not show significant differences $(\cong 0.35 \mathrm{~V})$ for both curves. In the open circuit potential versus time curves can be observed an increasing of potential, suggesting the film formation on the metallic material immersed in electrolyte solution [14]. Several authors have described an improvement of corrosion resistance of $\mathrm{Au}$ and $\mathrm{Pd}$ ( $>5 \%$ content) in commercial gold-silver alloys immersed in chloride solution. On the contrary, Ag, In and Cu metals suffer preferential attack on this condition $[15,16]$.

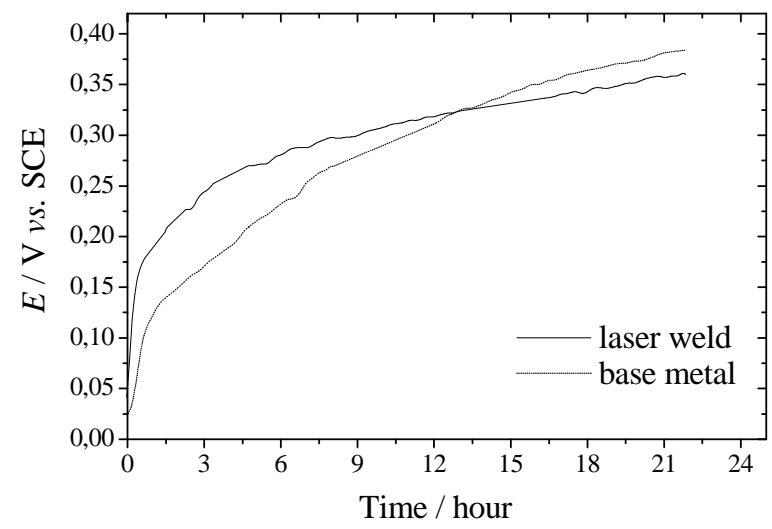

Figure 2. Open circuit potential versus time curves obtained for AuPdAgIn alloy in $0.9 \% \mathrm{NaCl}$ solution.

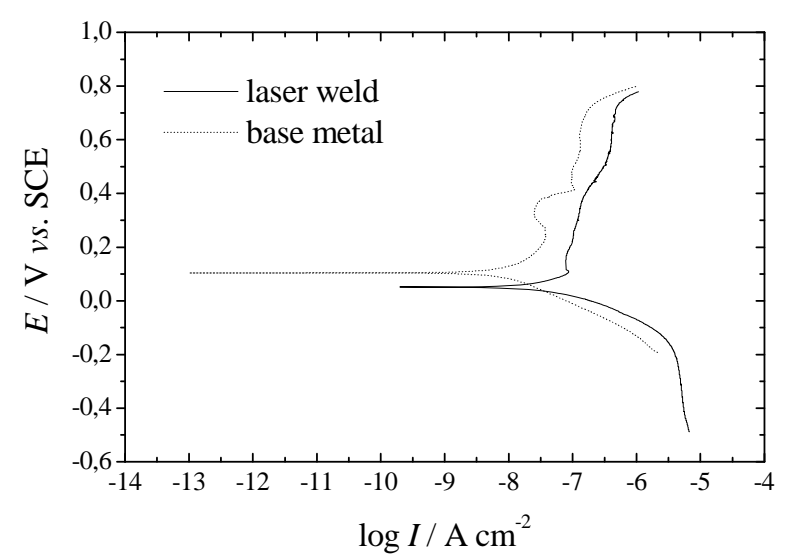

Figure 3. Potentiodynamic polarization curves obtained for AuPdAgIn alloy in $0.9 \% \mathrm{NaCl}$ solution.
Figure 3 shows the potentiodynamic polarization curves of metal base and welding areas. It can be observed a straight electroactive range. An extensive passivation range of +0.1 to $+0.8 \mathrm{~V}$ (ECS) with a passive current variation ( 0.1 to $1 \mu \mathrm{A} \cdot \mathrm{cm}^{-2}$ ) was observed for the metal base area. A corrosion potential of, approximately, $+0.1 \mathrm{~V}$ was obtained for the welding area. This corrosion potential value was $50 \mathrm{mV}$ higher than those for metal base area $(+0.053 \mathrm{~V})$. The passivity range was significantly ample range for both areas. However, it was obtained a lower passive current $\left(0.01\right.$ to $\left.0.1 \mu \mathrm{A} \cdot \mathrm{cm}^{-2}\right)$, indicating an improvement of corrosion resistance of the material, probably, due to microstructure of the welding area. In addition, a low current oscillation could be observed in the welding area from 0.3 to $0.4 \mathrm{~V}$. In the potentiodynamic polarization curves was observed that behavior could be associate to an increase of passive layer thickness probably of $\mathrm{AuCl}_{3}$ and posterior breakdown and repassivation [14]. For both situations, there was a breakdown of passive layer around $+0.8 \mathrm{~V}$ without pitting corrosion. Brugirard, et al. have observed higher Ag dissolution rate than Pd using gold alloys based on silver-palladium in artificial saliva [17]. Meyer and Reclaru have reported the corrosion resistance of noble metal alloys for dental applications. They have investigated that the alloys for preparing full-metal crowns and bridges are somewhat less corrosion resistant than the newer alloys for the metal-ceramic technique. This difference is explained by the higher content of noble metals in the alloys for ceramic veneering, or by the relatively high content of non-noble metals (silver, copper, zinc) in the alloys for crowns and bridges. It was also observed that the presence of cadmium or nickel has a distinctive (and highly degradative) effect on the corrosion behavior, whereas base-metals such as In and Ga do not affect significantly the resistance to corrosion in the alloys for metal-ceramic veneering [18]. According to other studies in literature, alloys with high proportions of Au were resistant to corrosion due to their high thermodynamic stability. However, many studies found that the Au ions were released [19].

The complex format of the impedance response obtained for AuPdAgIn alloy presents two distorted semicircles within the studied frequency range, Figure 4. The diameter of each capacitive arc shows that the base metal area (Figure 4(a)) has a higher corrosion resistance value than the laser weld joint, Figure 4(b). Both of the impedance spectra were also influenced by a diffusion response, which can be observed by a straight line at low frequencies $[6,20,21]$. These spectra were fitted using the model of equivalent electrical circuit with two terms $R(\mathrm{CPE})$ in series, indicating possible occurrence of at least two successive electrochemical processes. The non- 

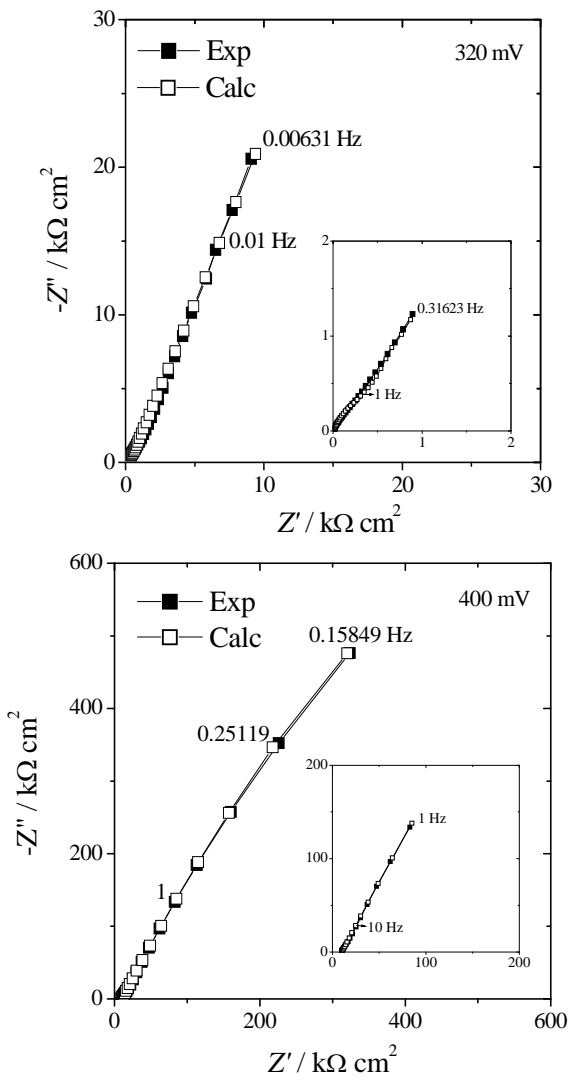

Figure 4. Complex plane spectra obtained for AuPdAgIn alloy in $0.9 \% \mathrm{NaCl}$ solution at the open circuit potential reached on the steady state: (a) metal base area; (b) laser weld.

ideal capacitances were modeled by $\mathrm{CPE}_{1}$ and $\mathrm{CPE}_{2}$, can be correlated with metallic corrosion and formation of oxide film, respectively at high and low frequencies. These values oscillated between $1-10 \mathrm{mF} \cdot \mathrm{cm}^{-2}$. The polarization resistance determined at low frequencies, $R_{\mathrm{p} 2}$ (in parallel with $\mathrm{CPE}_{2}$ ), was considerably higher for laser weld area $\left(\cong 2 \mathrm{M} \Omega \cdot \mathrm{cm}^{2}\right)$ than base metal $\left(\cong 5 \mathrm{k} \Omega \cdot \mathrm{cm}^{2}\right)$. Meyer and Reclaru observed that the polarization resistance reached values of order of $\mathrm{M} \Omega$, using an alloy with approximately $40 \%$ of $\mathrm{Au}$ in its compositions [18,20].

\section{Conclusions}

The laser weld presented a refined dendritical microstructure while the base metal showed a biphasic granular microstructure. The potentiodynamic profiles were considerably similar to both areas observed. However, the area of the laser weld presented corrosion potential slightly superior when compared to the one of the base metal. In both cases, a response of linear impedance was observed at low frequencies, including a non-uniform diffusion. The values of $R_{\mathrm{p}}$ by impedance suggest the best resistant corrosion behavior for laser weld.

\section{Acknowledgements}

Thanks to the Laboratory VAIAZZI (SP, Brazil) and a doctoral grant from FAPESP.

\section{REFERENCES}

[1] D. A. Givan, "Precious Metals in Dentistry," Dental Clinics North America, Vol. 51, No. 3, 2007. pp. 591-601. doi:10.1016/j.cden.2007.03.005

[2] W. J. O`Brien, "Dental Materials and Their Selection,” Quintessence Publishing Co. Inc., Hanover Park, 2002.

[3] R. A. Flinn and P. K. Trojan, "Engineering Materials and Their Applications,” Houghton Mifflin Company, Boston, 1990.

[4] R. Zupanic, A. Legat and N. Funduk, "Tensile Strength and Corrosion Resistance of Brazed and Laser-Welded Cobalt-Chromium Alloy Joints," Journal of Prosthetic Dentistry, Vol. 96, No. 4, 2006, pp. 273-282. doi:10.1016/j.prosdent.2006.08.006

[5] H. Wulfes, "Precision Milling and Partial Denture Constructions,” Academia Dental, Lakewood, 2003.

[6] M. L. Santos, H. A. Acciari, L. C. O. Vercik and A. C. Guastaldi, "Laser Weld: Microstruture and Corrosion Study of Ag-Pd-Au-Cu alloy of Dental Application,” Materials Letters, Vol. 57, No. 13-14, 2003, pp. 1888-1893. doi:10.1016/S0167-577X(02)01095-9

[7] R. G. Kelly, D. W. Shoesmith and R. G. Buchheit, "Electrochemical Techniques in Corrosion Science and Engineering,” Marcel Dekker, New York, 2003.

[8] F. Mansfeld, H. Shih, H. Greene and C. H. Tsai, "Analysis of EIS Data Common Corrosion Processes,” In: J. R. Scully, D. C. Silverman and M. W. Kending, Eds., Electrochemical Impedance: Analysis and Interpretation, American Society for Testing and Materials, Philadelphia, 1993. doi:10.1520/STP18062S

[9] A. Legat and V. Dolecek, "Chaotic Analysis of ElectroChemical Noise Measured on Stainless Steel," Journal of the Electrochemical Society, Vol. 142, No. 6, 1995, pp. 1851-1858. doi:10.1149/1.2044205

[10] A. Legat, "Influence of Electrolyte Movement on Measured Electrochemical Noise,” Corrosion, Vol. 56, No. 11, 2000, pp. 1086-1092. doi:10.5006/1.3294393

[11] D. Sun, P. Monaghan, W. A. Brantley and W. M. Johnston, "Electrochemical Impedance Spectroscopy Study of High-Palladium Dental Alloys. Part I. Behavior at Open Circuit Potential," Journal of Materials Science: Materials in Medicine, Vol. 13, No. 5, 2002, pp. 435-442. doi:10.1023/A:1014719513624

[12] R. W. Phillips, “Materiais Dentários,” Guanabara Koogan, Rio de Janeiro, 1993.

[13] P. C. R. D. Souza, J. C. Dinato, C. R. S. Beatrice, A. C. Guastaldi and M. A. Bottino, "Soldagem na Odontologia: Estudo de Uniões Soldadas Empregando-se Laser e Brasagem,” Revista da Associação Paulista de Cirurgiões Dentistas, Vol. 54, No. 5, 2000, pp. 470-475. 
[14] T. P. Hoar and D. C. Mears, "Corrosion-Resistant Alloys in Chloride Solutions: Materials for Surgical Implants," Proceedings Royal Society London Series, Vol. 294, No. 18, 1966, pp. 486-511. doi:10.1098/rspa.1966.0220

[15] D. L. Johnson, V. W. Rinne and L. L. Bleich, "Polarization-Corrosion Behavior of Commercial Gold and Silver-Base Casting Alloys in Fusayama Solution,” Journal of Dental Research, Vol. 62, No. 12, 1983, pp. 1221-1225. doi:10.1098/rspa.1966.0220

[16] N. K. Sarkar, R. A. Fuys and J. W. Stanford, "The Chloride Corrosion Behavior of Silver-Base Casting Alloys," Journal of Dental Research, Vol. 58, No. 6, 1979, pp. 1572-1577. doi:10.1177/00220345790580060501

[17] J. Brugirard, R. Bargain, J. C. Dupuy, H. Mazille and G. Monnier, "Study of the Electrochemical Behavior of Gold Dental Alloys,” Journal of Dental Research, Vol. 52, No. 4, 1973, pp. 828-836. doi:10.1177/00220345730520043001

[18] J. M. Meyer and L. Reclaru, "Electrochemical Determination of the Corrosion-Resistance of Noble Dental Cast- ing Alloys,” Journal of Materials Science: Materials in Medicine, Vol. 6, No. 9, September 1995, pp. 534-540. doi:10.1007/BF00151035

[19] G. A. Zarb and J. M. Symington, "Osseointegrated Dental Implants: Preliminary Report on a Replication Study," Journal of Prosthetic Dentistry, Vol. 50, No. 2, August 1983, pp. 271-276. doi:10.1016/0022-3913(83)90029-X

[20] M. L. Santos, "Estudo de Corrosão de Juntas Soldadas a Laser e Brasagem Utilizando-se Ligas Metálicas Odontológicas Empregadas em Próteses Sobre Implantes,” MSc dissertation, Instituto de Química de Araraquara, Universidade Estadual Paulista, Araraquara, 2002.

[21] H. A. Acciari, A. C. Guastaldi and C. M. A. Brett, "Corrosion of the Component Phases Presents in High Copper Dental Amalgams. Application of Electrochemical Impedance Spectroscopy and Electrochemical Noise Analysis," Corrosion Science, Vol. 47, No. 3, March 2005, pp. 635-647. doi:10.1016/j.corsci.2004.07.004 